\title{
A DBR framework for designing mobile virtual reality learning environments
}

\author{
Thomas Cochrane, Stuart Cook, Stephen Aiello, Duncan Christie, David Sinfield, Marcus Steagall, \\ and Claudio Aguayo \\ Auckland University of Technology
}

\begin{abstract}
This paper proposes a design based research (DBR) framework for designing mobile virtual reality learning environments. The application of the framework is illustrated by two design-based research projects that aim to develop more authentic educational experiences and learner-centred pedagogies in higher education. The projects highlight the first two phases of the DBR framework, involving the exploration of mobile virtual reality (VR) to enhance the learning environment, and the design of prototype solutions for the different contexts. The design of the projects is guided by a set of design principles identified from the literature.
\end{abstract}

\section{Introduction}

Kopcha, Schmidt, and McKenney (2015) define three types of educational design research (EDR) studies based upon the three phases of McKenney and Reeves (2012) generic model of EDR. These include:

1. Analysis and exploration studies that focus on understanding educational problems through analysis of the literature, stakeholders, and context.

2. Design and construction studies that focus on presenting design frameworks along with the theoretical and empirical grounding that gives them shape.

3. Evaluation and reflection studies that describe the practical and scientific implications that result from formative and/or summative evaluations of designed interventions (Kopcha et al., 2015, p. i).

Educational design research (EDR) is often used synonymously with design-based research (DBR), and we use the term DBR in this paper. This paper falls within Kopcha et al's. (2015), category of design and construction studies, and reports on the design phase of developing and implementing a DBR framework to design mobile virtual reality (VR) and augmented reality (AR) learning environments. Our framework uses a DBR methodology involving a 4-phase iterative approach that explores an educational scenario, informed by the literature, to identify design principles to develop potential solutions through multiple cycles of analysis, design and implementation, evaluation, and redesign. Through collaboration between researchers and practitioners, DBR aims to develop transferable design principles that can then be used within other educational contexts. DBR was chosen as a foundation for the design framework because it represents a pragmatic research methodology for dealing with real world learning contexts (Amiel \& Reeves, 2008; Wang \& Hannafin, 2005). The design framework (Cochrane, 2016; Cochrane, Narayan, \& Antonczak, 2016) utilises an ecology of mobile social media resources to capture and share usergenerated VR environments from authentically designed contexts using a 360-degree camera, such as the Nikon Keymission360, with interactivity added via platforms such as SeekBeak, for viewing on smartphones via a Google Cardboard compatible head mounted display (HMD). Mobile VR is a rapidly emerging technology, and our framework aims to be flexible enough to accommodate these rapid changes.

In this paper the DBR framework is illustrated by two example research projects: Mesh360, and the Augmented Classroom projects. The context of the projects includes:

- $\quad$ a 3 year degree in paramedicine or critical care education in a New Zealand university, and

- $\quad$ a 3 year degree in visual design in a New Zealand university.

Both courses focus on preparation of students for participation within professional communities, and thus are founded upon ontological pedagogies that connect knowing, doing, and being as students reconceptualise their role from learner to active participant within a professional community in a rapidly changing world. 


\begin{abstract}
A genuine higher education cannot content itself with a project either of knowledge or of skills, or even of both. It has to do with being, for it is being that is fundamentally challenged in and by a world of supercomplexity. Neither knowledge nor skills can furnish the wherewithal to form persons adequate to such a situation: on the one hand, knowledge will not just be out of date, but will always be insufficient to describe the novel and unstable situations that present themselves; on the other hand, skills are always addressed to known situations, and cannot be addressed to unforeseen (and unforeseeable) situations. So (human) being itself has to come into view, for the fundamental problem now becomes: how is one to live amid supercomplexity? (Barnett, 2009, p. 439)
\end{abstract}

The aim of our first example, the Multiple Environment Simulation Hub (mesh360) project, is to explore the use of VR to enhance paramedicine education through the development of more authentic simulation scenarios and exercises than previously used. Globally emergency services are being transformed by the ubiquity of mobile social media (Lyon, 2013; Szczerba, 2014; United Nations Educational, Scientific and Cultural Organization [UNESCO], 2013). As an essentially mobile profession of first responders to emergencies on location, paramedicine can benefit from mobile technologies, that enable communication, link to remote medical knowledge databases, record on the scene experiences, simulate hazardous environments, and use mobile piloted drones for quickly exploring inaccessible crash and disaster scenes. The use of VR for medical and critical care training has been established for over a decade (Hsu et al., 2013) as a means to simulate hazardous environments and provide students with problem based learning scenarios. VR in medical education ranges from dedicated simulation programs through to virtual environments in Second Life (Conradi et al., 2009). A comparative study by Cone, Serra, and Kurland (2011) indicated the efficacy of VR as a platform for paramedic student education. The main challenges of VR in medical education are the development costs and user familiarity with the VR-based applications (Conradi et al., 2009; Hsu et al., 2013). A focus on student-generated mobile VR and social media can address these issues. Medical education is already engaging with mobile social media through such avenues as the \#foamed (https://twitter.com/hashtag/FOAMed?src=hash) Twitter hashtag (free open access medical education), and the annual Social Media and Critical Care (SMACC) Conference (http://www.smacc.net.au/about-us/welcome/), first held in 2013 and now attracting more than 2000 attendees.

The aim of the second example, the Augmented Classroom project, is for visual design students to augment their creative visual designs through geolocation of their projects on a group collaborative Google Map; including the creation and sharing of a spherical 360 panorama of their artwork, creation and sharing of a short-form video introducing their project, and a long-form online video exploration of their project ideas. The rationale for the project is based upon the increasingly changing role of the graphic designer faced with adapting to new methods and technologies (Bower, Howe, McCredie, Robinson, \& Grover, 2013). Traditional print based media faces a shrinking user market as users develop a preference for the flexible and ubiquitous access to multimedia enhanced content via their personal mobile devices. Similarly, mobile touch screen devices have become established as graphic design creation tools (Sinfield, 2013). For example, one of the key new features of the recently released iPad Pro is the integration of a virtual pencil and advanced drawing mode sensors. However, it is possible to use mobile VR to create virtual interactive art exhibitions including still or moving images, and to enhance traditional graphics representations via image-triggered actions. Yang (2015) commenting on a VR painting exhibition states: "Tools and software like Tilt Brush has the potential to revolutionize visual design just like when Photoshop and Illustrator did years ago” (p. 3). The potentially burgeoning market for VR content will require VR content developers, thus presenting graphic designers with another career path option. Creating authentic learning experiences for graphic design students to learn these skills will require new pedagogical strategies beyond the traditional portfolio studio exhibition and critique. Mobile $\mathrm{AR}$ and VR can enhance graphic design student learning experiences by linking the showcase of their work to a much wider international community audience.

As illustrated by these two examples, we argue that curriculum design should go beyond substituting new technologies into pre-existing pedagogical strategies that are focused upon teacher-delivered content to exploring new pedagogical strategies that enable student-determined learning or heutagogy (Hase \& Kenyon, 2007). To ensure that the projects are founded in pedagogical goals rather than technology focused, we have established a community of practice (CoP) around each project. Each CoP is comprised 
of lecturers and academic advisors to base the projects within a collaborative design-based research methodology. This begins with the observations of student threshold concepts in each context, as outlined above, and is followed by ideation and prototyping of technology-enhanced solutions. The following phases of the research projects explore mobile VR as a simple approach for students to create, share, and critique real world experiences linked to the geographical context that simulated environments tend to decontextualise. Clearly one of the main challenges of such an approach to student-generated VR content revolves around the ethical issues of participant anonymity and confidentiality - particularly in the context of paramedicine. However, critical care often occurs in very visible public contexts, and learning to deal with this aspect of critical care is essential. Ethical consent for both projects has been obtained through the university ethics committee.

\section{Literature review}

VR exists on an experiential continuum from spanning from real world environments to experiencing an immersive simulated environment. Fitzgerald et al. (2013) represent this continuum from reality to VR as a mixed reality approach that ranges from interaction with real environments, to AR, through to virtual environments. While we have previously explored a similar framework for designing mobile AR learning environments (Cochrane, Narayan, et al., 2016), the focus of this paper is on implementing a framework for designing mobile VR learning environments, introduced in a previous paper (Cochrane, 2016).

\section{Theoretical foundations}

\section{Foundational learning theories}

The framework is founded upon networked, ambient/experiential, and student-centred pedagogies that support the development of student reconceptions of being: from learners to active participants within their chosen profession. Examples of networked, ambient/experiential and student-centred pedagogies include: social constructivism (Vygotsky, 1978), mixed reality learning (Pachler, Bachmair, \& Cook, 2010), connectivism (Siemens, 2004), rhizomatic learning (Cormier, 2008), and heutagogy (Hase \& Kenyon, 2001). These pedagogies focus on developing student creativity, collaboration, and connecting teams of students. The role of the lecturer changes from that of content creator and delivery to designer of learning experiences and environments that facilitate student creativity, team work, and partnership in the learning process (Danvers, 2003).

\section{Learner generated content and contexts}

Luckin et al. (2010) and Pachler et al. (2010) argue that one of the key affordances of mobile learning is the ability to enable learner-generated content and learner-generated contexts. This aligns with a key element of enabling student-determined learning (heutagogy) and creativity, that involves designing learning experiences that develop student capability to navigate novel problems (Blaschke \& Hase, 2015; Hase \& Kenyon, 2007). This involves activities and processes the learner, not just the teacher, undertakes. In medical education developing students' critical clinical analysis skills is of high importantance. Moving beyond textbook information and scenarios, to enable students to develop and critique authentic contexts for diagnosis is critical. This is the aim of clinical placement and simulations, however critical analysis and linking theory to practice can be achieved through designing learning experiences around problem based learning and learner generated content and contexts, leading to the development of student critical analysis skills. Examples of authentic mobile clinical analysis projects in the literature include: Conradi et al. (2009), Eysenbach (2008), Ming-Zher, Swenson, and Picard (2010), Scott, Nerminathan, Alexander, Phelps, and Harrison (2015), and Smordal and Gregory (2003). In the context of visual design education, todays' students need to develop capability as VR content creator experts as they prepare for a profession that increasingly moves beyond print-based media to enhanced user interactivity and immersion (Sinfield, 2013).

\section{Design principles}

We have identified several design principles throughout the body of mobile learning and educational technology literature that support the key graduate outcomes of a course of study (Cochrane \& Narayan, 2015; Herrington, Herrington, \& Mantei, 2009; Laurillard, 2012; Leinonen \& Durall, 2014). Activity theory is one of the most common theoretical frameworks used to inform mobile learning research and practice, however, Pachler et al. (2010) argue that it is difficult to operationalise and is more suitable as an analytical tool than a pedagogical design tool. Bannan, Cook, and Pachler (2015) argue that DBR is an 
appropriate methodology for grounding mobile learning projects and research. Thus, design principle one is to use design-based research as a methodology.

Throughout the design and implementation of more than 40 mobile learning projects, we have found that supporting the development of innovative pedagogies through the integration of educational technology projects via the establishment of a CoP, is key to the success of such projects (Cochrane, 2014). Therefore, design principle two supports projects through the establishment of CoPs.

Hase and Kenyon (2007) argue the case for using heutagogy (student-determined learning) as a guiding pedagogical framework to go beyond developing student competency, to building student capacity to deal with real world problems. In the messy arena of clinical diagnosis, the ability to think beyond familiar scenarios and to work effectively in teams is critical. Similarly, key attributes for a design graduate include the ability to be a creative and self-directed learner. Hence design principle three is to use heutagogy as a guiding pedagogical framework.

Herrington et al. (2009) argue that any educational technology intervention should be designed around the authentic use of the technology. Reeves (2015) also highlights the imperative to move beyond simple comparative educational technology studies. This leads to design principle four: our mobile VR projects must be authentic and not simply substitution of current practice.

St John-Matthews (2016) argues for the need to integrate collaboration and team-work into student project activities via harnessing social media to network and share research and practice. Thus our final design principle is to integrate collaboration and teamwork into the projects.

In summary, the design principles (DPs) we identified through the literature for designing authentic mobile learning and scaffolding innovative pedagogies include:

DP1: Basing the project within a design-based research methodology (Bannan et al., 2015; Cook \& Santos, 2016)

DP2: Supporting the project through the establishment of a CoP (Cochrane, 2014; Cochrane \& Narayan, 2016b)

DP3: Using heutagogy (student-determined learning) as a guiding pedagogical framework (Blaschke \& Hase, 2015; Hase, 2014)

DP4: Designing around the authentic use of mobile devices and VR (Burden \& Kearney, 2016; Cochrane \& Narayan, 2017; Kearney, Schuck, Burden, \& Aubusson, 2012)

DP5: Integrate collaboration and team-work into the project activities (Kearney et al., 2012; Organisation for Economic Co-operation and Development [OECD], 2015)

\section{Methodology}

Informed by DP1, the framework is founded upon a qualitative design-based research methodology (Amiel \& Reeves, 2008). Each project is supported by a CoP that meets weekly face-to-face, consisting of a group of lecturers an academic advisor and a research and technology facilitator (DP2), an online project discussion forum (Google Plus Community), an online collaborative documentation archive (via Google Docs), a Wordpress site that acts as a project social media hub, and a project social media hashtag (for example: \#mesh360, \#southsideresearch) for curating the lecturer and student-created VR panoramas, 360 videos, and other mobile social media contents and outputs (DP3, DP4, and DP5). The discipline based COPs collaborate as part of a wider distributed network via participation in a connectivist MOOC (cMOOC), mobile social media learning technologies (MOSOMELT) facilitated by the academic advisor, and prepared by a Certified Member of the Association for Learning Technologies (CMALT) portfolios, based upon their project experiences (Cochrane \& Narayan, 2016a; Cochrane, Narayan, Burcio-Martin, Lees, \& Diesfeld, 2015). Data collection processes include: a record of researcher and lecturer collaborative design of new assessment activities and processes via shared Google Docs; collation of researcher and lecturer brainstorming and sharing processes via the public (but participation by invitation only) Google Plus community; face-to-face and video conferenced semi-structured interviews; collation of mobile social media via a project hashtag; and online surveys. Participant social media usage is analysed via visual conversational analysis tools such as TAGSExplorer (Hawksey, 2011) for Twitter. Other social media usage analytics such as Google Street View and YouTube views and peer ratings 
provide analysis of the geographic reach and impact of the project artefacts. The third and final stage of the projects will involve student data analysis. This will occur after the exam board has finalised all academic grades, with the data analysed by the researchers for themes indicating the impact on student learning and the development of professional digital literacies.

\section{Research questions}

Our research questions focus upon using mobile VR to enable new pedagogies that redefine the role of the teacher, the learner, and of the learning context:

1. How can we use our identified design principles to utilise a mash up of mobile social media as a simple framework to design learner-generated authentic learning environments?

2. How can we enhance educational environments using mobile VR to more authentically reflect real world scenarios?

\section{Project participants}

The first DBR phases of the project include three paramedicine lecturers, three visual design lecturers, an academic advisor as pedagogical and technological support, and a research and VR production facilitator. The implementation and evaluation phase of the project includes the current cohort of paramedicine and visual design students.

A preliminary survey of lecturers from a variety of discipline contexts attending workshops and symposia facilitated by the research team exploring mobile VR was conducted to explore prior experience and conceptions regarding mobile $\mathrm{VR}$ in their educational practice (https://www.surveymonkey.com/results/SM-2PKP9P3N/). The survey gathered 51 responses, with results indicating a general lack of prior experience and low-level conceptualisation of the application of mobile VR in higher education. Mobile adoption was high with $100 \%$ of respondents owning multiple mobile devices (smartphone 100\%, tablet 100\%, laptop 73\%), and 71\% had experienced mobile VR via Google Cardboard or a compatible HMD. However, less than 20\% had used a 360 camera to create VR content. There was wide personal adoption of mobile applications and social media, but a corresponding low rate of educational use of these tools, with only Twitter (72\%), Skype (58\%), eBooks (56\%), and collaborative document sharing (52\%) reaching over $50 \%$ adoption. Respondents identified with a wide range of learning theories and frameworks. Multiple responses were allowed, with four theories dominating: social constructivism (67\%), constructivism (65\%), problem based learning (57\%), and authentic learning (55\%). Respondents were asked to describe a potential application of mobile VR for student-generated projects within their discipline context. Most answers focused on enabling enhanced simulation experiences and authentic virtual field trips within a variety of discipline contexts. These results validated the need for a mobile VR design framework to guide lecturers in designing mobile VR learning environments.

\section{DBR framework}

We have applied McKenney and Reeves (2012) generic model of educational design research to the context of designing mobile AR and VR learning environments. Figure 1 outlines the generic EDR model aligned to the key supporting mobile learning theories and frameworks. 


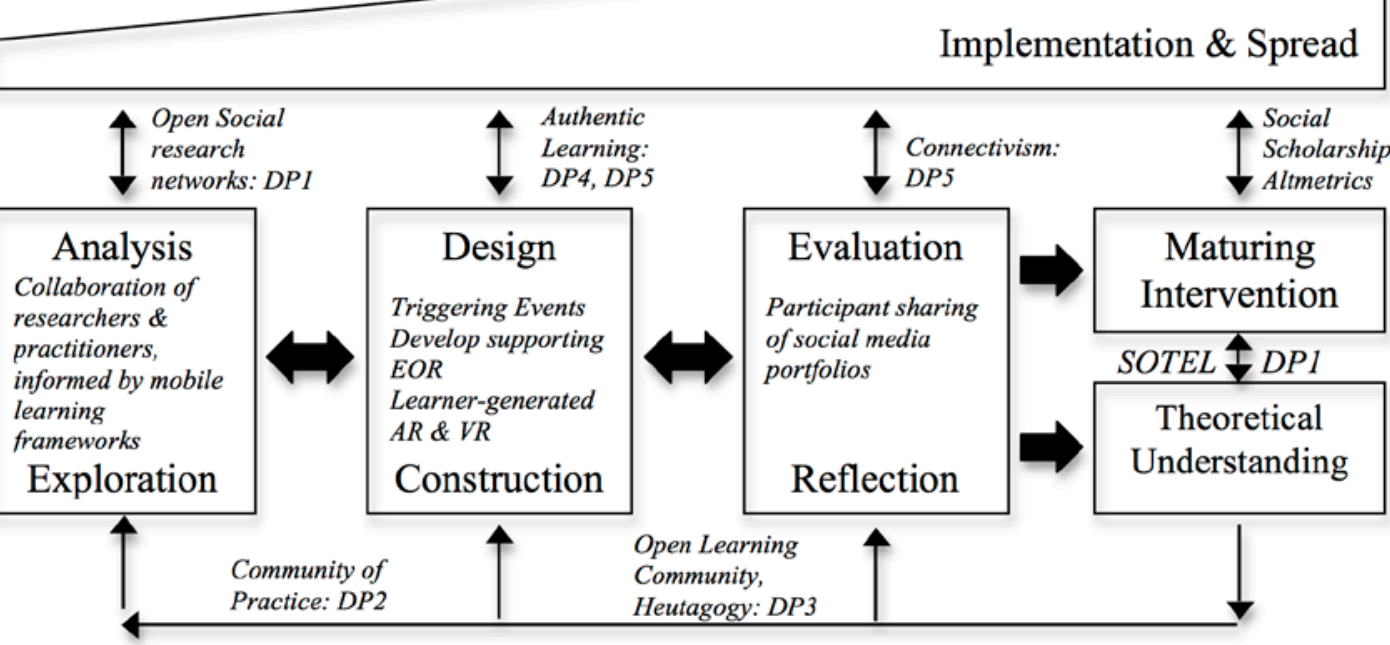

Figure 1. Generic model of EDR (McKenney \& Reeves, 2012, p. 159) applied to our mobile learning framework

Note. DPs added to the diagram in italics.

While McKenney and Reeves (2012) do not assign a separate phase to the wider dissemination and evaluation of research (they label this maturing intervention and theoretical understanding in their generic model), we follow Bannan, Cook, and Pachler (2015) in assigning this as a fourth DBR phase via Haynes' (2016) definition of the scholarship of technology enhanced learning (SoTEL). The goal of our framework is to enable the explicit design of learning experiences around new pedagogies such as rhizomatic learning, social constructivism, heutagogy, authentic and ambient learning, and connectivism, via user-generated mobile VR. Table 1 illustrates the crossover between the four phases of design-based research, learning design, design thinking, and the relationship with theory, practice, and mobile learning.

Table 1

DBR framework for mobile $V R$

\begin{tabular}{|l|l|l|l|l|}
\hline $\begin{array}{l}\text { Methodology: } \\
\text { (Educational) } \\
\text { Design-based } \\
\text { research }\end{array}$ & Phase 1 & Phase 2 & Phase 3 & Phase 4 \\
\hline $\begin{array}{l}\text { Four stages of } \\
\text { learning design }\end{array}$ & $\begin{array}{l}\text { Informed } \\
\text { exploration }\end{array}$ & Enactment & $\begin{array}{l}\text { Evaluation: } \\
\text { Local impact }\end{array}$ & $\begin{array}{l}\text { Evaluation: } \\
\text { Broader impact }\end{array}$ \\
\hline $\begin{array}{l}\text { Connecting theory } \\
\text { and practice }\end{array}$ & Theory & Practice & $\begin{array}{l}\text { Participant } \\
\text { feedback }\end{array}$ & Critical reflection \\
\hline $\begin{array}{l}\text { Intersection with } \\
\text { mobile learning }\end{array}$ & $\begin{array}{l}\text { Mobile learning } \\
\text { framework } \\
\text { informing } \\
\text { curriculum } \\
\text { redesign }\end{array}$ & $\begin{array}{l}\text { Rhizomatic } \\
\text { learning: } \\
\text { Developing an } \\
\text { ecology of } \\
\text { resources (EOR) } \\
\text { Designing } \\
\text { triggering events }\end{array}$ & $\begin{array}{l}\text { Participant } \\
\text { feedback }\end{array}$ & $\begin{array}{l}\text { Peer reviewed } \\
\text { feedback via } \\
\text { SOTEL }\end{array}$ \\
\hline Design thinking & $\begin{array}{l}\text { Observe and } \\
\text { define }\end{array}$ & $\begin{array}{l}\text { Ideate and } \\
\text { prototype }\end{array}$ & $\begin{array}{l}\text { Iterative testing } \\
\text { and improvement }\end{array}$ & Wider testing \\
\hline
\end{tabular}

This paper outlines the first two DBR phases of each research project where we co-define the project problem and requirements, and develop prototype solutions based on existing design principles and technological innovation. Cormier (2008) refers to the design of a collection of tools to support learning as an EOR. A generic mobile VR ecology of resources is designed to support each project consisting of a bricolage of mobile social media tools that facilitate five key elements associated with our identified design principles: (1) a student team hub, (2) a mobile VR content creation platform, (3) a cloud-based 
VR content host, (4) VR content publication and sharing via social networks (SNS), and (5) a smartphone-driven head mounted display. Figure 1 provides an example collection of mobile social media and social networks as an ecology of resources to support the creation and sharing of usergenerated mobile VR as part of the projects.

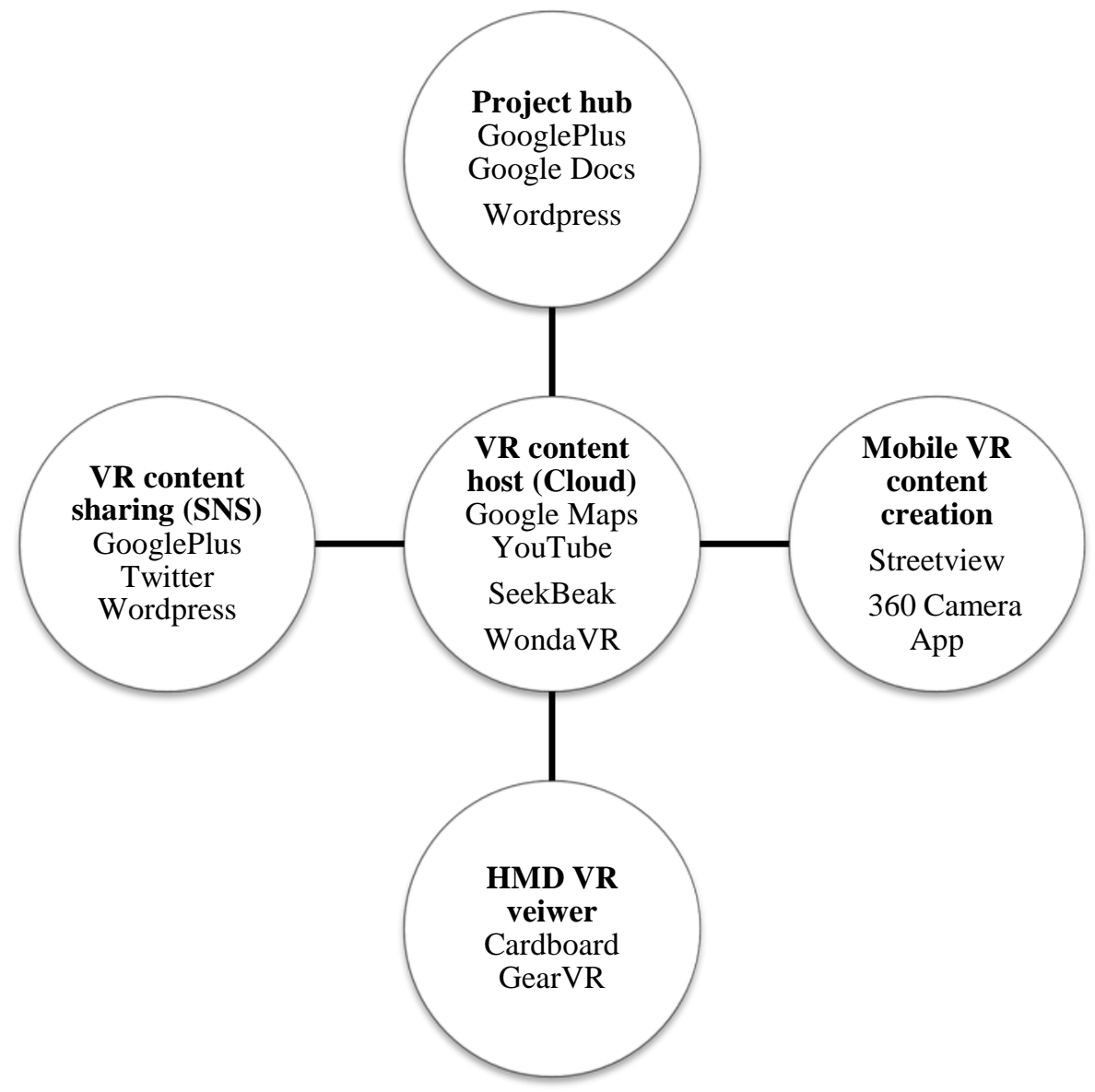

Figure 1. Mobile VR ecology of resources

In our case the ecology of resources utilised to support the two projects include:

- individual Wordpress blogs as project journals,

- $\quad$ a team Wordpress blog for publicising project outputs (e.g., http://meshVR.wordpress.com),

- a shared Google Drive folder for project documentation, collaborative research writing, and collaborative curriculum brainstorming, and redesign,

- a Google Plus community,

- a project YouTube channel,

- $\quad$ SeekBeak - VR creation and publication platform,

- WondaVR creation software and app distribution, and

- $\quad$ a social media hashtag (for example: \#mesh360, \#southsideresearch).

The mobile VR ecology of resources provides both a bricolage of community building and nurturing tools for the projects, and a rich source of participant-generated artefacts and reflections from both lecturers and students. The mobile EORs support the design of triggering events for stimulating student discussion and collaboration. In choosing platforms for each element of the framework we have focused upon selecting cross-platform tools that enable a student BYOD approach and interconnect easily. A simple and flexible delivery platform for student-generated mobile VR content is key - and therefore we have chosen Google Maps and YouTube as suitable mobile VR content hosts that do not require any specialised institutional web server, minimises the project IT infrastructure, and provides the opportunity 
for either private or global collaboration. Testing of the implementation of the first phases of this framework is illustrated by the following two example projects (Mesh360 and Augmenting the Classroom).

\section{Mesh360 project implementation}

The aim of the Mesh360 project is to utilise the potential of virtual reality by providing an immersive learning environment for novice paramedicine students to try, fail, and learn without real-life consequences. The aim is to provide an environment that can help develop a student's understanding and critical analysis of the complexities found within pre-hospital paramedic practice. Due to the nature of the wide and dynamic working environment that a paramedic might encounter, it is important to provide an authentic learning experience for the practice of problem solving, skills, and judgement. It is important that all components of a teaching system, especially the teaching methods used and the assessment tasks are aligned with the learning activities assumed in the intended outcomes. In order to ask this, we employed the concepts of heutagogy, and rhizomatic learning in the design of real world simulation scenarios using mobile VR.

The Mesh360 project consists of three identified sequential elements:

(1) Orientation: VR 360-degree simulated environment within a head mounted display (HMD) driven by a participant's smartphone is designed to develop a student's critical awareness of real world issues and risk prior to entering the clinical simulation room,

(2) Clinical simulation: Enhanced 360-degree interactive images will be projected within the immersive simulation training room and will provide authentic environments for Paramedic clinical practice, and

(3) Integration and use of mobile social media into the curriculum to facilitate student-generated content and authentic simulation contexts as more realistic assessment activities.

\section{Pre-simulation VR scenarios}

Typically, when a paramedic responds to an emergency there is an initial period of analysis based on the information provided and this helps to formulate a potential management plan prior to arrival. This precontact analysis is currently difficult to translate into the simulation environment and limits the ability for the paramedic student to visualise or experience the broader scene. When engaged in manikin-based simulations the instructor will feed or prompt information to the student verbally. Whilst this shows benefit, it is often left to the imagination and can hinder true analysis, and disrupt plan making and the learning process. Given that paramedics work in an ever-changing environment and gain knowledge from all information provided in addition to the nuances of the scene, it is important to develop a learning environment that provides a more authentic context. The Mesh360 project aims to give the student a 360degree immersive view of the scene prior to, and within, the scenario to allow the student to receive prompts from the scene and formulate a plan of action. This allows the student to gain information from an authentic environment and to make informed decisions during the simulation. By engaging in a 360degree immersive VR experience the student is in a learning environment where they can truly experience, interact, and learn, as they critically explore the scene, preparing them for real world experiences. The early prototype of this project can be viewed using a smartphone and an HMD: https://youtu.be/7bUDIWQX60Q.

The goal of this project is for students to learn to interpret the critical care environments they are called to in the real world. This will help with critical decision-making and ultimately the care and treatment of their patient. Example prototype mobile 360 scenarios are:

- $\quad$ https://seekbeak.com/v/2lVjKrZzBby

- $\quad$ https://seekbeak.com/v/NA0zr4JqvQL

- 360 YouTube Channel https://www.youtube.com/channel/UCmY4u7ub5k2pgGUqZ1B7Pig 


\section{Implementing the framework design principles}

The application of the mobile VR framework within the context of paramedicine education is illustrated in Table 2.

Table 2

Applying a mobile VR framework in paramedicine education

\begin{tabular}{|l|l|l|}
\hline \multirow{2}{*}{ Design Principles } & Design of learning experiences & \multicolumn{2}{|l|}{ Triggering events } \\
\cline { 2 - 3 } $\begin{array}{l}\text { DP1: Embed a DBR } \\
\text { methodology }\end{array}$ & $\begin{array}{l}\text { Support lecturer culture of } \\
\text { exploration, and iterative design } \\
\text { and evaluation via participation } \\
\text { within communities such as } \\
\text { ResearchGate, and CMALT }\end{array}$ & $\begin{array}{l}\text { Collaboration between lecturers and } \\
\text { academic researchers, participation } \\
\text { in MOSOMELT cMOOC. }\end{array}$ \\
\hline $\begin{array}{l}\text { DP2: Establishment of } \\
\text { CoP }\end{array}$ & $\begin{array}{l}\text { Collaboration tools for project } \\
\text { planning: e.g. Google Plus } \\
\text { community, Google Docs }\end{array}$ & $\begin{array}{l}\text { Design new curriculum } \\
\text { Gather feedback through SOTEL } \\
\text { Publication of projects }\end{array}$ \\
\hline DP3: Heutagogy & $\begin{array}{l}\text { Negotiated ecology of resources } \\
\text { enabling student-generated } \\
\text { content: 360-degree camera rig } \\
\text { and stitching software }\end{array}$ & $\begin{array}{l}\text { Assessment activities designed as a } \\
\text { series of triggering events to } \\
\text { stimulate student crisis awareness } \\
\text { and develop a professional global } \\
\text { network within critical care. } \\
\text { Students form critical care response } \\
\text { teams and negotiate team roles. }\end{array}$ \\
\hline $\begin{array}{l}\text { DP4: Authentic learning: } \\
\text { Situated content }\end{array}$ & $\begin{array}{l}\text { Shared 360 video: e.g., YouTube } \\
\text { 360 via HMD e.g., Google } \\
\text { Cardboard }\end{array}$ & $\begin{array}{l}\text { Students identify potential hazards } \\
\text { within a simulated critical care 360- } \\
\text { degree scenario before entering the } \\
\text { physical simulation space. }\end{array}$ \\
\hline $\begin{array}{l}\text { DP4: Authentic learning: } \\
\text { Situated context }\end{array}$ & $\begin{array}{l}\text { 360-degree immersive } \\
\text { environment simulation }\end{array}$ & $\begin{array}{l}\text { Emergency response care is } \\
\text { embedded within an authentically } \\
\text { simulated virtual environment. }\end{array}$ \\
\hline team work & Plus, Facebook, and Twitter & $\begin{array}{l}\text { Students connect with peers and } \\
\text { experts globally via the \#foamed } \\
\text { Twitter hashtag and the SMACC } \\
\text { conference. }\end{array}$ \\
\hline
\end{tabular}

In this scenario paramedicine students form critical care response teams, negotiate team roles, and create simulated critical care scenarios located within geographic contexts (e.g., via Google Streetview) in preparation for their practical critical care assessments. The practical assessments are linked to authentic contexts via a pre-practice VR experience of the scenario where they identify potential hazards and environmental risks, before entering the simulation room.

Initial peer feedback on the project has been gathered through presentation and discussion at the Ascilite 2016 conference (Cochrane, Cook, Aiello, Harrison, \& Aguayo, 2016; Cochrane, Jones, Kearney, Farley, \& Narayan, 2016).

\section{Augmenting the classroom project implementation}

Visual design education typically emulates the Atelier physical design studio environment. The Atelier learning environment is especially suited to the visual communication model as it deals with the creative processing of ideas that needs to be shared in a collaborative manner. This has proven a successful model over the years, but has more recently seen a shift in thinking as we move into a more digital model of learning and away from the constraints of the classical classroom structure (Brown, 2006; Thomas \& Brown, 2011). This project focuses on exploring AR and VR technologies to expand the dimensions of the classical design studio classroom beyond its physical limits. Beginning with simple social media AR/VR via the likes of Google Street view panoramas, provides students with a conceptual framework on which to build the integration of these BYOD technologies into their projects. 
Using the area of Manukau, South Auckland, New Zealand as a region for inspiration, the students chose a location that had a significant meaning to them. The students were asked to explore these spaces and places, and travel through its streets and alleyways, looking for details, colours, textures, ideas, and meanings, and capture these using 360 panoramas and spherical Streetview images. The students' work comprised a set of three visual elements (a series of posters, documented publication, 3D object) with the visual representation being presented in an augmented manner in a virtual environment. The students were asked to take panoramic images of their chosen area and upload them to Google Streetview using their own devices. This was a collaborative process with all the students in the class sharing their images and their visual content onto an openly shared Google Map. The map received 313 views in only a few weeks. Example prototype mobile 360 scenarios:

- $\quad$ https://seekbeak.com/v/xXw1beyq5ka

- Collaborative Map http://tinyurl.com/z9u4xxu

\section{Implementing the framework design principles}

The application of the mobile VR framework within the context of visual design education is illustrated in Table 3.

Table 3

Applying a mobile VR framework in visual design education

\begin{tabular}{|c|c|c|}
\hline \multirow[t]{2}{*}{ Design Principles } & \multicolumn{2}{|l|}{ Design of learning experiences } \\
\hline & Ecology of resources & Triggering events \\
\hline DP1: DBR methodology & $\begin{array}{l}\text { Support lecturer culture of } \\
\text { exploration, and iterative design } \\
\text { and evaluation via participation } \\
\text { within communities such as } \\
\text { ResearchGate, and CMALT }\end{array}$ & $\begin{array}{l}\text { Collaboration between lecturers and } \\
\text { academic researchers, participation } \\
\text { in MOSOMELT cMOOC }\end{array}$ \\
\hline $\begin{array}{l}\text { DP2: Establishment of } \\
\text { CoP }\end{array}$ & $\begin{array}{l}\text { Collaboration tools for project } \\
\text { planning: e.g., Google Plus } \\
\text { community, Google Docs }\end{array}$ & $\begin{array}{l}\text { Design new curriculum } \\
\text { Gather feedback through SOTEL } \\
\text { Publication of projects }\end{array}$ \\
\hline DP3: Heutagogy & $\begin{array}{l}\text { Negotiated ecology of resources } \\
\text { enabling student-generated } \\
\text { content: 360-degree camera rig } \\
\text { and stitching software }\end{array}$ & $\begin{array}{l}\text { Assessment activities designed as a } \\
\text { series of triggering events to } \\
\text { stimulate student creativity and link } \\
\text { authentic contexts to student } \\
\text { generated content. Students form a } \\
\text { community of practice to design an } \\
\text { authentic interactive virtual } \\
\text { exhibition. }\end{array}$ \\
\hline $\begin{array}{l}\text { DP4: Authentic learning: } \\
\text { Situated content }\end{array}$ & $\begin{array}{l}\text { Shared } 360 \text { video: e.g., YouTube } \\
360\end{array}$ & $\begin{array}{l}\text { The student-generated 360-degree } \\
\text { content is uploaded and shared for } \\
\text { peer critique. }\end{array}$ \\
\hline $\begin{array}{l}\text { DP4: Authentic learning: } \\
\text { Situated context }\end{array}$ & HMD: e.g., Google Cardboard & $\begin{array}{l}\text { A global audience can experience the } \\
\text { virtual exhibition event linked to the } \\
\text { original geographic context }\end{array}$ \\
\hline $\begin{array}{l}\text { DP5: Collaboration and } \\
\text { team work }\end{array}$ & $\begin{array}{l}\text { Community hub: e.g., Google } \\
\text { Plus, Facebook, and Twitter }\end{array}$ & $\begin{array}{l}\text { A global audience can engage in a } \\
\text { critique and feedback of the virtual } \\
\text { exhibition. }\end{array}$ \\
\hline
\end{tabular}

In this scenario students' artwork and designs are showcased within interactive virtual 360-degree exhibitions that are linked directly to the originating context. This provides the students with an authentic canvas on which to present their work, as well as an authentic context for viewers to experience. Initial peer feedback on the project has been gathered through presentation and discussion at the ICERI 2016 conference and the MINA2016 Symposium (Cochrane, Sinfield, Steagall, \& Tolutau, 2016; Steagall, Sinfield, Cochrane, \& Tolutau, 2016). 


\section{Discussion}

Key to our DBR framework for designing mobile virtual reality learning environments is the close collaboration between the discipline lecturers and educational researchers/advisors, informed by our first two DPs. In a similar manner, Laurillard (2012) argues that curriculum design should be seen as a design science, and become a collaborative process (Laurillard et al., 2013). We apply this in our design framework through the application of DP2 - the formation of supportive communities of practice around each project. DPs 5 and 6 are reified through linking these projects into an authentic international experience via the integration of participation within a network of lecturer professional development COPs through a cMOOC that supports participants' compilation of a portfolio for submission towards CMALT accreditation. This approach embeds the scholarship of technology enhanced learning (SOTEL) within the DBR methodology guiding the design of these projects (DP1). This approach enables the development of the conceptual shifts around pedagogy and practice that create a foundation for redesigning the curriculum to support student-determined learning environments (DPs 3 and 4).

The framework leverages mobile VR as the tools to mediate these changes in activity and communication within learning communities. Engagement with an emergent and rapidly changing technology ecosystem such as mobile VR creates a learning culture that can become responsive and comfortable with change and the supercomplexity of the world into which our graduates enter (Barnett, 2012). Reflecting upon the iterative implementation and evaluation of our projects will inevitably lead to refinement of the DPs.

\section{Refinement of the DPs}

Throughout the initial DBR phases of the project we have attempted to use our identified DPs to guide the project:

- $\quad$ basing the project within a design-based research methodology,

- $\quad$ supporting the project through the establishment of a CoP,

- $\quad$ using heutagogy (student-determined learning) as a guiding pedagogical framework,

- $\quad$ designing around the authentic use of mobile devices and VR, and

- $\quad$ integrating collaboration and teamwork into the project activities.

The DBR methodology forms the foundational link between the iterative project stages (Table 1). The establishment of the CoP supported by online collaborative platforms and weekly face-to-face meetings has allowed for the facilitated implementation and running of the DBR methodology agenda in addressing mobile VR in the contexts of paramedicine and visual design education. The analysis of practical problems and development of DPs through constant testing and refinement of prototype solutions in authentic practice is enhanced by the ongoing collaborative and co-creative structure of the CoP and its associated ecology of resources. This has also permitted rapid adaptation to the constantly changing nature of available mobile VR technological affordances. As an example, since the start of the Mesh360 and Augmenting the Classroom projects in early 2016, we went from no availability of 360 cameras in New Zealand, to access to a range of 360 cameras and associated creation and production software and sharing platforms, for example, the 2016 release of the Samsung Gear 360 camera, and the release of the LG 360 camera. Mobile VR content creation and sharing platforms have also developed rapidly. For example, Google Streetview, YouTube 360 video, Pano2VR, Seekbeak, WondaVR, and Thinglink.

Integration of heutagogy as a guiding pedagogical framework has been possible in part due to the practitioners committing to collaboratively explore and experience new pedagogical strategies using mobile VR technology within their specific educational contexts. By addressing their authentic needs in context, the practitioners have collaborated to develop their own prototype solutions and learning environments supported by participation within a CoP, resulting in the design and sharing of unique solutions to meeting the changing world into which paramedicine and visual design graduates now enter.

\section{Project implementation and evaluation phases}

The establishment of the Mesh360 and Augmenting the Classroom CoPs, and initial development of theoretical VR solutions (DBR phases 1 and 2) have shown positive outcomes allowing for the emergence of a set of prototype solutions currently being tested in practice. These outcomes and the prototype set of 
solutions will inform the next phases in the DBR project (phases 3 and 4), involving the implementation of prototype VR scenarios and various student-generated projects. Student feedback on these prototypes will inform further design iterations, and we aim to gather wider peer feedback via further conference presentations and peer-reviewed publication of our results, effectively embedding the SoTEL into the projects. This set of feedback and evaluation instances will permit the development of a final set of DPs for the implementation and use of mobile VR technology and associated affordances, in the provision of transformative and enhanced learning experiences in higher education.

\section{Limitations and future directions}

Our research questions focus on using mobile VR to enable new pedagogies that redefine the role of the teacher, the learner, and of the learning context. By focusing upon a BYOD approach to learner-generated VR we are keeping the financial investment in the project to the students to a minimum. However, there is significant time involved in establishing the projects and familiarising ourselves with new tools and platforms constantly being released. We believe the investment will be worthwhile, in terms of both value for money in the enhanced learning experience, and the benefits of the professional development of the lecturers. We are also hopeful that our experiences will be useful in other educational contexts and discipline areas, which can design their own VR enhanced learning environments based upon our developing DBR model supported by a sustained CoP. A limitation of the project is the emergent nature of mobile VR technologies that are undergoing rapid development and change, generating much interest but requiring significant professional development for lecturers to conceptualise the educational potential of these mobile VR learning environments.

\section{Conclusions}

This paper presents a framework for designing mobile virtual reality learning environments illustrated by two work-in-progress projects. The projects highlight the first two phases of a DBR framework exploring mobile VR and 360-degree video enhanced simulation environments for authentic paramedicine and visual design education scenarios. The goal of these enhanced learning environments is the development of student critical thinking and analysis skills in the rapidly changing world they will enter as graduates. Preparing students to have the capability to work within these environments requires a more authentic approach to education than a traditional classroom or clinical simulation environment. Keeping us on track within the project scope and goals is our foundational DBR methodology and a commitment to heutagogy as a guiding pedagogy. In the next phase of the project we will move beyond ideation and prototyping to the implementation, and evaluation of mobile VR and enhanced simulation-learning experiences.

\section{References}

Amiel, T., \& Reeves, T. (2008). Design-based research and educational technology: Rethinking technology and the research agenda. Educational Technology \& Society, 11(4), 29-40.

Bannan, B., Cook, J., \& Pachler, N. (2015). Reconceptualizing design research in the age of mobile learning. Interactive Learning Environments, 24(5), 1-16. https://doi.org/10.1080/10494820.2015.1018911

Barnett, R. (2009). Knowing and becoming in the higher education curriculum. Studies in Higher Education, 34(4), 429-440. https://doi.org/10.1080/03075070902771978

Barnett, R. (2012). Learning for an unknown future. Higher Education Research \& Development, 31(1), 65-77. https://doi.org/10.1080/07294360.2012.642841

Blaschke, L., \& Hase, S. (2015). Heutagogy, technology, and lifelong learning for professional and parttime learners. In A. Dailey-Hebert, \& K. S. Dennis (Eds.), Transformative perspectives and processes in higher education (Vol. 6, pp. 75-94). Switzerland: Springer International Publishing.

Bower, M., Howe, C., McCredie, N., Robinson, A., \& Grover, D. (2013, 1-4 Oct. 2013). Augmented reality in Education; Cases, places, and potentials. Paper presented at the Educational Media (ICEM), 2013 IEEE 63rd Annual Conference International Council, Singapore.

Brown, J. S. (2006). New learning environments for the 21st century: Exploring the edge. Change: The Magazine of Higher Learning, 38(5), 18-24. https://doi.org/10.3200/CHNG.38.5.18-24 
Burden, K., \& Kearney, M. (2016). Conceptualising authentic mobile learning. In D. Churchill, J. Lu, K. F. T. Chiu, \& B. Fox (Eds.), Mobile learning design: Theories and application (pp. 27-42). Singapore: Springer.

Cochrane, T. (2014). Critical success factors for transforming pedagogy with mobile Web 2.0. British Journal of Educational Technology, 45(1), 65-82. https://doi.org/10.1111/j.1467-8535.2012.01384.x

Cochrane, T. (2016). Mobile VR in education: From the fringe to the mainstream. International Journal of Mobile and Blended Learning (IJMBL), 8(4), 45-61. https://doi.org/10.4018/IJMBL.2016100104

Cochrane, T., Cook, S., Aiello, S., Harrison, D., \& Aguayo, C. (2016, 28-30 November). Designing virtual reality environments for paramedice education: MESH360. Paper presented at the Show Me The Learning Ascilite Conference, Adelaide.

Cochrane, T., Jones, S., Kearney, M., Farley, H., \& Narayan, V. (2016). Beyond Pokemon Go: Mobile AR \& VR in education. In S. Barker, S. Dawson, A. Pardo, \& C. Colvin (Eds.), Show me the learning (pp. 136-138). Adelaide: Ascilite. Retrieved from http://2016conference.ascilite.org/wpcontent/uploads/ascilite2016_cochrane_symposium.pdf.

Cochrane, T., \& Narayan, V. (2015). Design considerations for mobile learning. In C. Reigeluth, B. J. Beatty \& R. Myers (Eds.), Instructional-design theories and models (Vol. 4, pp. 385-414). New York, NY: Routledge.

Cochrane, T., \& Narayan, V. (2016a). Evaluating a professional development cMOOC: MOSOMELT. In S. Barker, S. Dawson, A. Pardo, \& C. Colvin (Eds.), Show me the learning (pp. 139-150). Adelaide: Ascilite. Retrieved from http://2016conference.ascilite.org/wpcontent/uploads/ascilite2016_cochrane_full_mon_pm.pdf.

Cochrane, T., \& Narayan, V. (2016b). Principles of modeling COPs for pedagogical change: Lessons learnt from practice 2006 to 2014. In J. McDonald \& A. Cater-Steel (Eds.), Implementing communities of practice in higher education: Dreamers and schemers (Vol. Part IV, pp. 619-643). Singapore: Springer.

Cochrane, T., \& Narayan, V. (2017). Design considerations for mobile learning. In C. Reigeluth, B. J. Beatty, \& R. Myers (Eds.), Instructional-design theories and models (Vol. 4, pp. 385-414). New York, NY: Routledge.

Cochrane, T., Narayan, V., \& Antonczak, L. (2016). A framework for designing collaborative learning environments using mobile AR. Journal of Interactive Learning Research, 27(4), 293-316.

Cochrane, T., Narayan, V., Burcio-Martin, V., Lees, A., \& Diesfeld, K. (2015, 29 November - 2 December). Designing an authentic professional development cMOOC. Paper presented at the 32nd Ascilite Conference: Globally Connected, Digitally Enabled, Perth.

Cochrane, T., Sinfield, D., Steagall, M., \& Tolutau, T. (2016, 30 November - 1 December). Exploring Mobile360: Immersive user-generated mobile images and video. Paper presented at the 6th Mobile Creativity and Mobile Innovation Symposium, Melbourne.

Cone, D. C., Serra, J., \& Kurland, L. (2011). Comparison of the SALT and Smart triage systems using a virtual reality simulator with paramedic students. European Journal of Emergency Medicine, 18(6), 314-321. https://doi.org/10.1097/MEJ.0b013e328345d6fd

Conradi, E., Kavia, S., Burden, D., Rice, A., Woodham, L., Beaumont, C., . . . Poulton, T. (2009). Virtual patients in a virtual world: Training paramedic students for practice. Medical Teacher, 31(8), 713-720. https://doi.org/10.1080/01421590903134160

Cook, J., \& Santos, P. (2016). Three phases of mobile learning state of the art and case of mobile help seeking tool for the health care sector. In D. Churchill, J. Lu, T. K. F. Chiu, \& B. Fox (Eds.), Mobile learning design (pp. 315-333), Singapore: Springer.

Cormier, D. (2008). Rhizomatic education: Community as curriculum. Innovate, 4(5). Retrieved from http://davecormier.com/edblog/2008/2006/2003/rhizomatic-education-community-as-curriculum/.

Danvers, J. (2003). Towards a radical pedagogy: Provisional notes on learning and teaching in art \& design. International Journal of Art \& Design Education, 22(1), 47-57. https://doi.org/10.1111/1468$\underline{5949.00338}$

Eysenbach, G. (2008). Medicine 2.0: Social Networking, Collaboration, Participation, Apomediation, and Openness. Journal of Medical Internet Research, 10(3). https://doi.org/10.2196/jmir.1030

FitzGerald, E., Ferguson, R., Adams, A., Gaved, M., Mor, Y., \& Thomas, R. (2013). Augmented reality and mobile learning: the state of the art. International Journal of Mobile and Blended Learning, 5(4), 43-58. https://doi.org/10.4018/ijmbl.2013100103

Hase, S. (2014). An introduction to self-determined learning (Heutagogy). In L. M. Blaschke, C. Kenyon, \& S. Hase (Eds.), Experiences in self-determined learning (Vol. Paperback and Kindle editions, pp. 19). CreateSpace Independent Publishing Platform. 
Hase, S., \& Kenyon, C. (2001). From Andragogy to Heutagogy. ultiBASE Articles, (December), 1-10. Retrieved from http://www.psy.gla.ac.uk/ steve/pr/Heutagogy.html

Hase, S., \& Kenyon, C. (2007). Heutagogy: a child of complexity theory. Complicity: An International Journal of Complexity and Education, 4(1), 111-118.

Hawksey, M. (2011). Twitter: How to archive event hashtags and create an interactive visualization of the conversation. Blog Retrieved from http://mashe.hawksey.info/2011/11/twitter-how-to-archive-eventhashtags-and-visualize-conversation/

Haynes, D. (2016). Introducing SOTEL. International Journal for the Scholarship of Technology Enhanced Learning, 1(1), 1-2.

Herrington, A., Herrington, J., \& Mantei, J. (2009). Design principles for mobile learning. In J. Herrington, A. Herrington, J. Mantei, I. Olney, \& B. Ferry (Eds.), New technologies, new pedagogies: Mobile learning in higher education (pp. 129-138). Wollongong: University of Wollongong.

Hsu, E. B., Li, Y., Bayram, J. D., Levinson, D., Yang, S., \& Monahan, C. (2013). State of virtual reality based disaster preparedness and response training. PLoS Currents, 5. https://doi.org/10.1371/currents.dis.1ea2b2e71237d5337fa53982a38b2aff

Kearney, M., Schuck, S., Burden, K., \& Aubusson, P. (2012). Viewing mobile learning from a pedagogical perspective. Research in Learning Technology, 20(14406), 1-17. https://doi.org/10.3402/rlt.v20i0.14406

Kopcha, T. J., Schmidt, M. M., \& McKenney, S. (2015). Editorial 31(5): Special issue on educational design research (EDR) in post-secondary learning environments. Australasian Journal of Educational Technology, 31(5), i-ix. https://doi.org/http://dx.doi.org/10.14742/ajet.2903

Laurillard, D. (2012). Teaching as a design science: Building pedagogical patterns for learning and technology. New York, NY: Routledge.

Laurillard, D., Charlton, P., Craft, B., Dimakopoulos, D., Ljubojevic, D., Magoulas, G., ... Whittlestone, K. (2013). A constructionist learning environment for teachers to model learning designs. Journal of Computer Assisted Learning, 29(1), 15-30. Retrieved from https://dx.doi.org/10.1111/j.13652729.2011.00458.x

Leinonen, T., \& Durall, E. (2014). Design thinking and collaborative learning. Comunicar, 42(1), 107115. https://doi.org/http://dx.doi.org/10.3916/C42-2014-10

Luckin, R., Clark, W., Garnett, F., Whitworth, A., Akass, J., Cook, J., ... Robertson, J. (2010). Learnergenerated contexts: A framework to support the effective use of technology for learning. In M. Lee, \& C. McLoughlin (Eds.), Web 2.0-based e-learning: Applying social informatics for tertiary teaching (pp. 70-84). Hershey, PA: IGI Global.

Lyon, J. (2013). The effectiveness of online and mobile technologies for changing health behaviours. Retrieved from http://www.ana.org.nz/sites/default/files/Final snapshot on mobile technologies.pdf

McKenney, S., \& Reeves, T. (2012). Conducting educational design research. London: Routledge.

Ming-Zher, P., Swenson, N. C., \& Picard, R. W. (2010). A wearable sensor for unobtrusive, long-term assessment of electrodermal activity. Biomedical Engineering, 57(5), 1243-1252. https://doi.org/10.1109/TBME.2009.2038487

Organisation for Economic Co-operation and Development (2015). Students, computers and learning. Paris: OECD Publishing.

Pachler, N., Bachmair, B., \& Cook, J. (2010). Mobile learning: Structures, agency, practices. London: Springer.

Reeves, T. C. (2015). Educational design research: Signs of progress. Australasian Journal of Educational Technology, 31(5), 613-620. https://doi.org/http://dx.doi.org/10.14742/ajet.2902

Scott, K. M., Nerminathan, A., Alexander, S., Phelps, M., \& Harrison, A. (2015). Using mobile devices for learning in clinical settings: A mixed-methods study of medical student, physician and patient perspectives. British Journal of Educational Technology, 48(1), 176-190. https://doi.org/10.1111/bjet.12352

Siemens, G. (2004). Connectivism: A learning theory for the digital age. eLearnspace. Retrieved from http://www.elearnspace.org/Articles/connectivism.htm

Sinfield, D. (2013). Graphic design in a digital world: Enhancing graphic design teaching through digital technologies. International Journal of Design Education, 7(1), 68-75.

Smordal, O., \& Gregory, J. (2003). Personal digital assistants in medical education and practice. Journal of Computer Assisted Learning, 19(3), 320-329.

Steagall, M., Sinfield, D., Cochrane, T., \& Tolutau, T. (2016, 14-16 November). Contextualising the classroom: Using Google Maps and 360 degree imagery to augment the undergraduate design 
environment. Paper presented at the 9th Annual International Conference of Education, Research, and Innovation, Seville, Spain.

St John-Matthews, J. (2016). Harnessing social media to network and share research. Journal of Medical Imaging and Radiation Sciences, 47(2), 121-123. https://doi.org/10.1016/j.jmir.2016.04.002Szczerba, R. (2014, 14 December). The future of HealthTech - Ambulance drones. Forbes Tech. Retrieved from http://onforb.es/1AxEl2w

Thomas, D., \& Brown, J. S. (2011). A new culture of learning: Cultivating the imagination for a world of constant change. CreateSpace Independent Publishing Platform.

United Nations Educational, Scientific and Cultural Organization (2013). UNESCO policy guidelines for mobile learning. Retrieved from http://unesdoc.unesco.org/images/0021/002196/219641E.pdf

Vygotsky, L. (1978). Mind in society. Cambridge, MA: Harvard University Press.

Wang, F., \& Hannafin, M. J. (2005). Design-based research and technology-enhanced learning environments. Educational Technology Research and Development, 53(4), 5-23. https://doi.org/10.1007/bf02504682

Yang, J. N. (2015). World's first virtual reality art exhibition with Tilt Brush. Retrieved from https://virtualrealityreporter.com/tilt-brush-virtual-reality-painting-art-exhibition-world-first/

Corresponding author: Thomas Cochrane, Thomas.cochrane@aut.ac.nz

Australasian Journal of Educational Technology (c) 2017.

Please cite as: Cochrane, T., Cook, S., Aiello, S., Christie, D., Sinfield, D., Steagall, M., \& Aguayo, C. (2017). A DBR framework for designing mobile virtual reality learning environments. Australasian Journal of Educational Technology, 33(6), 54-68. https://doi.org/10.14742/ajet.3613 